\title{
Remember that patient you saw last week: characteristics and frequency of patients experiencing anticipated and unanticipated death following ED discharge
}

\author{
Richard Hoang 1,2 $^{10} \cdot$ Kari Sampsel ${ }^{3,4} \cdot$ Andrew Willmore $^{3,4} \cdot$ Katerina Yelle Labre $^{4}$. \\ Venkatesh Thiruganasambandamoorthy ${ }^{3,4,5} \cdot$ Lisa A. Calder ${ }^{5}$
}

Received: 11 January 2021 / Accepted: 6 August 2021 / Published online: 29 September 2021

(c) The Author(s), under exclusive licence to Canadian Association of Emergency Physicians (CAEP)/ Association Canadienne de Médecine d'Urgence (ACMU) 2021

\begin{abstract}
Background The emergency department (ED) is an at-risk area for medical error. We determined the characteristics of patients with unanticipated and anticipated death within 7 days of ED discharge and whether medical error contributed. Methods We performed a single-centre health records review of 200 consecutive cases during a 3-year period from 2014 to 2017 in two urban, academic, tertiary care EDs. We included patients evaluated by an emergency physician who were discharged and died within 7 days. Three trained and blinded reviewers determined if deaths were related to the index visit, anticipated or unanticipated, and/or due to potential medical error. Reviewers performed content analysis to identify themes. Results Of 200 cases, 129 had sufficient information for analysis, translating to 44 deaths per 100,000 ED discharges $(200 / 458,634) .13$ cases per 100,000 ED discharges $(58 / 458,634)$ were related and unanticipated deaths. 4 cases per 100,000 were due to potential medical errors $(18 / 458,634)$. Over half $(52.7 \%)$ of 129 patients displayed abnormal vital signs at discharge. Pneumonia (27.1\%) was the most common cause of death. Patient themes were: difficult historian, multiple complaints, multiple comorbidities, acute progression of chronic disease, and recurrent falls. Provider themes were: failure to consider infectious etiology, failure to admit high-risk elderly patient, and missed diagnosis. System themes were: multiple ED visits or recent admission, and no repeat vital signs recorded.

Conclusion Though the frequency of related and unanticipated deaths and those due to medical error was low, clinicians should carefully consider the highlighted common patient, provider, and system themes to facilitate safe discharge from the ED.
\end{abstract}

Keywords Patient safety $\cdot$ Medical error $\cdot$ Emergency department $\cdot$ Discharge

\section{Résumé}

Contexte Le service des urgences (SU) est un secteur à risque pour les erreurs médicales. Nous avons déterminé les caractéristiques des patients dont le décès a été anticipé ou non dans les 7 jours suivant la sortie des urgences et si une erreur médicale y a contribué.

Richard Hoang

rich.nguyen.hoang@gmail.com

1 Department of Emergency Services, Sunnybrook Health

Sciences Centre, Toronto, ON, Canada

2 University of Toronto, Toronto, ON, Canada

3 Department of Emergency Medicine, The Ottawa Hospital, Ottawa, ON, Canada

4 University of Ottawa, Ottawa, ON, Canada

5 The Ottawa Hospital Research Institute, Ottawa, ON, Canada 
Méthodes Nous avons réalisé une étude monocentrique des dossiers médicaux de 200 cas consécutifs sur une période de trois ans, de 2014 à 2017, dans deux urgences urbaines, universitaires et de soins tertiaires. Nous avons inclus les patients évalués par un médecin urgentiste qui sont sortis de l'hôpital et sont décédés dans les 7 jours. Trois examinateurs formés et en aveugle ont déterminé si les décès étaient liés à la visite de référence, anticipés ou non, et/ou dus à une erreur médicale potentielle. Les examinateurs ont effectué une analyse de contenu pour identifier les thèmes.

Résultats Sur 200 cas, 129 disposaient d'informations suffisantes pour l'analyse, ce qui correspond à 44 décès pour 100 000 sorties des urgences (200/458 634). 13 cas pour 100000 sorties des urgences (58/458 634) étaient des décès liés et imprévus. 4 cas pour 100000 étaient dus à des erreurs médicales potentielles (18/458 634). Plus de la moitié $(52,7 \%)$ des 129 patients présentaient des signes vitaux anormaux à la sortie de l'hôpital. La pneumonie $(27,1 \%)$ était la cause de décès la plus fréquente. Les thèmes des patients étaient les suivants: patient difficile, plaintes multiples, comorbidités multiples, progression aiguë d'une maladie chronique et chutes récurrentes. Les thèmes abordés par les prestataires étaient les suivants: omission de tenir compte de l'étiologie infectieuse, omission d'admettre un patient âgé à haut risque et omission de diagnostic. Les thèmes du système étaient les suivants: visites multiples à l'urgence ou admission récente, et aucun signe vital répété n'a été enregistré.

Conclusion Bien que la fréquence des décès liés et imprévus et ceux dus à une erreur médicale soit faible, les cliniciens doivent examiner attentivement les thèmes communs mis en évidence pour les patients, les prestataires et les systèmes afin de faciliter une sortie en toute sécurité des urgences.

\section{Clinician's capsule}

What is known about the topic?

The emergency department (ED) is an at-risk area for medical error which could affect the outcomes of discharged patients.

\section{What did this study ask?}

We determined the characteristics of patients with unanticipated death within 7 days of ED discharge and whether medical errors occurred.

\section{What did this study find?}

Several common patient, provider, and systems themes were found in patients with unanticipated deaths that were related to previous ED discharge.

\section{Why does this study matter to clinicians?}

Clinicians should carefully consider the highlighted common patient, provider, and systems themes to facilitate safe discharge from the ED.

\section{Introduction}

The emergency department (ED) is an area of increased risk for medical error causing preventable death [1,2]. Patients who are treated in the ED are discharged, and subsequently die can experience medical error [3] and there have been efforts to identify such cases to improve ED care [4, 5].

A U.S. study identified four themes in patients who died after ED discharge due to preventable medical error: atypical presentation of an unusual problem; chronic disease with decompensation; abnormal vital signs; and conditions decreasing the likelihood of return for worsening symptoms [2]. Another U.S. study found the leading causes of death in patients who died soon after ED discharge to be atherosclerotic heart disease, myocardial infarction, and COPD. They identified altered mental status, dyspnea, and malaise/fatigue as common presenting complaints [4].

This is an exploratory study adding a unique Canadian perspective, aimed to determine the frequency and characteristics of patients experiencing death within 7 days after ED discharge and whether possible medical error occurred.

\section{Methods}

We conducted a single-centre health records review over a 3-year period from 2014 to 2017 in two urban, academic, tertiary care EDs. We included all patients evaluated by an emergency physician who were discharged home and died within 7 days. We used a cutoff of 7 days post-discharge to facilitate comparisons with previous studies $[2,4,8]$.

For inclusion, deaths must have been recorded in the study sites' electronic medical records (death certificate or discharge summary). We selected a consecutive sample of the most recent 200 cases for analysis. There were 458,634 ED visits during this timeframe. We excluded patients who lacked sufficient data for analysis (Supplement 1). The study site EDs are divided into 4 areas: resuscitation, emergent care, observation, and urgent care (Supplement 2). This study was approved by the Ottawa Health Science Network Research Ethics Board.

\section{Data analysis}

Three blinded reviewers [RH, KS, and AW] independently analyzed each case's medical records. Kappa values were not calculated. Reviewers underwent training to form a standardized process. Reviewers independently determined if deaths were related or unrelated to the index ED visit and 
whether they were anticipated or unanticipated (Supplement 3). Reviewers then applied the Modified Harvard Medical Practice Study criteria to determine if potential medical error occurred $[1,7]$. These criteria have been validated in previous ED studies [6-10]. Reviewers then independently performed content analysis, noting prominent themes related to the patient, presentation, diagnosis, and possible causes of error. The analyses were discussed at regular intervals with any discrepancies resolved by consensus agreement ( $<5$ disputes). Labels were established for recurrent themes.

\section{Results}

Of the 200 cases reviewed, 129 cases yielded sufficient information for analysis (Supplement 1). Insufficient information was primarily due to incomplete documentation. Baseline characteristics between patient groups were similar (Supplement 3). The total deaths, related and unanticipated deaths, and deaths possibly related to medical error within 7 days of ED discharge per 100,000 ED patients discharged are summarized in Table 1.

Table 1 The frequency of different death categories and the percentage of total deaths, related and unanticipated deaths, and unrelated and/or anticipated deaths according to chief complaint, discharge diagnosis, and cause of death

\begin{tabular}{|c|c|c|c|}
\hline Deaths & & Total & $\begin{array}{l}\text { Per } \\
100,000 \\
\text { ED visits }\end{array}$ \\
\hline Overall deaths & & 200 & 44 \\
\hline Related deaths & & 94 & 20 \\
\hline Unanticipated deaths & & 79 & 17 \\
\hline Related and unanticipated deaths & & 58 & 13 \\
\hline Deaths due to medical error & & 18 & 4 \\
\hline Percentage of... & Total deaths $(\%, N=129)$ & $\begin{array}{l}\text { Related and unanticipated deaths (\%, } \\
N=58)\end{array}$ & $\begin{array}{l}\text { Unrelated and/or } \\
\text { anticipated deaths (\%, } \\
N=71)\end{array}$ \\
\hline \multicolumn{4}{|l|}{ Chief complaint } \\
\hline Dyspnea & 22.5 & 24.1 & 21.1 \\
\hline General weakness & 14.0 & 13.8 & 14.1 \\
\hline Abdominal pain & 6.2 & 5.2 & 7.0 \\
\hline Head injury & 4.7 & 3.4 & 5.6 \\
\hline Nausea/vomiting & 3.9 & 6.9 & 1.4 \\
\hline \multicolumn{4}{|l|}{ Discharge diagnosis } \\
\hline Pneumonia & 9.3 & 8.8 & 8.5 \\
\hline Minor trauma w/o head injury & 6.2 & 5.3 & 7.0 \\
\hline $\mathrm{CHF}$ & 5.0 & 7.0 & 4.2 \\
\hline Malignant neoplasm & 5.4 & 1.8 & 8.5 \\
\hline Head injury & 4.7 & 5.3 & 4.2 \\
\hline Abdominal pain & 3.9 & 3.5 & 4.2 \\
\hline Asthma/COPD & 3.9 & 3.5 & 4.2 \\
\hline Dyspnea & 3.9 & 0.0 & 7.0 \\
\hline Chest pain & 3.1 & 5.3 & 1.4 \\
\hline Malaise/fatigue & 3.1 & 1.8 & 4.2 \\
\hline \multicolumn{4}{|l|}{ Cause of death } \\
\hline Pneumonia/aspiration & 27.1 & 24.1 & 29.6 \\
\hline Myocardial infarction & 10.1 & 8.6 & 11.3 \\
\hline Metastatic cancer & 7.8 & 1.7 & 12.7 \\
\hline Heart failure & 5.4 & 10.3 & 1.4 \\
\hline Asthma/COPD & 4.7 & 6.9 & 2.8 \\
\hline Intracranial bleed & 3.9 & 6.9 & 1.4 \\
\hline Ischemic bowel & 3.1 & 5.2 & 1.4 \\
\hline
\end{tabular}

Note that not all documented causes of death are included in the table, only the more frequent causes 
The observation area received most patients who died within 7 days of ED discharge (57.3\% of total deaths), while the urgent care area received a disproportionately large number of patients with related and unanticipated deaths (19.0\% of related and unanticipated deaths, compared to $4.2 \%$ of unrelated and/or anticipated deaths) (Supplement 5).

Over half $(52.7 \%, N=68)$ of those who died within 7 days of ED discharge had abnormal vital signs at discharge. Of these, $42.6 \%(N=29)$ had hypoxia or requirement for supplemental oxygen. Of these, only $27.6 \%(N=8)$ were on home oxygen, $13.8 \%(N=4)$ had low baseline oxygen saturation due to underlying medical comorbidities. Other abnormal discharge vital signs included tachycardia $(35.2 \%, N=24)$, tachypnea $(17.6 \%, N=12)$, and hypertension $(14.7 \%$, $N=10)$.

Dyspnea was the most common chief complaint $(22.5 \%$, $N=29$ ) (Supplement 6). Pneumonia was the most common discharge diagnosis $(9.3 \%, N=12)$ (Supplement 7) and the most common cause of death overall $(27.1 \%, N=35)$ (Table 1).

We noted two categories of themes among patients whose death was unanticipated and related to the index ED visit: (1) patient-related themes: difficult historian (concurrent illness altering ability to communicate or documentation of "difficult historian"), multiple comorbidities ( $\geq 3$ ), acute progression or decompensation of chronic disease, and recurrent falls; (2) system-related themes: multiple ED visits or recent admission, no repeat vital signs recorded.

Among patients whose death was possibly due to medical error, we identified these additional common themes: (1) patient-related themes: multiple complaints; (2) providerrelated themes: failure to consider infectious etiology, failure to admit high-risk elderly patient, missed diagnosis. Missed diagnoses were mostly infections (e.g., pneumonia, urinary tract infection, and biliary tract infection). Of the missed diagnoses, imaging discrepancies (missed diagnosis of pneumonia, $N=6$ ) emerged as a theme with only half resulting in a documented follow-up call.

\section{Discussion}

\section{Interpretation of findings}

Unanticipated and related deaths within 7 days of ED discharge were infrequent, as were those secondary to medical error. Pneumonia and myocardial infarction were the most common causes of death. These are high-risk diagnoses, especially in elderly patients. For example, a mismatch was noted between pneumonia as a discharge diagnosis (9.3\%) and cause of death $(27.1 \%)$, suggesting underdiagnosis. A disproportionate number of related and unanticipated deaths occurred among patients seen in the urgent care area; this could be explained by the cognitive bias of "geography is destiny" (i.e. assuming patients seen in lower acuity areas must have low acuity conditions). A common theme was failure to admit high-risk elderly patients. Many cases involved minor trauma leading to missed hip or rib fractures (leading to further falls or decompensation at home) or falls that were assumed to be mechanical and not worked up for cardiac or infectious cause, resulting in the discharge of elderly patients with pneumonia, for example.

\section{Comparison to previous studies}

We found the frequency of total patient deaths within 7 days of ED discharge to be 44 per 100,000 discharges $(200 / 458,634)$, while Obermeyer et al. found 120 per 100,000 [4]. The difference in total number of deaths and most common cause of death (pneumonia vs. atherosclerotic heart disease) between our study and that of Obermeyer et al. can likely be accounted for by the different study populations, healthcare systems, and sampling differences. We found the frequency of related and unanticipated deaths to be 13 per 100,000 ED discharges $(58 / 458,634)$ and deaths due to possible medical error to be 4 per 100,000 ED discharges $(18 / 458,634)$. Similarly, Sklar et al. found the frequency of related and unanticipated deaths to be 15 per 100,000 ED discharges and deaths due to possible medical error to be 5 per 100,000 [2]. We identified similar themes compared to Sklar et al.'s findings [2].

\section{Clinical implications}

Patients seen in the urgent care area represented the majority of patients who did not have repeat or discharge vital signs recorded. This is not surprising given the emphasis on patient turnover here. Our data combined with previous studies [2] support the practice of repeating vital signs if abnormal and carefully considering abnormal vitals prior to discharge. Clinicians should ensure timely re-assessments to facilitate early detection of decompensation even in ambulatory patients. Health systems should examine whether appropriate staffing balances with time pressures and workload. Thematic analysis revealed several patients with possible medical error contributing to their death had missed diagnoses that were most commonly due to failure to consider an infectious etiology as well as imaging misinterpretation by the emergency physician. This suggests that current quality assurance systems should be re-evaluated to ensure adequate patient follow-up for missed results. 


\section{Research implications}

The themes identified can guide further hypothesis-driven research to prevent or mitigate care issues and reduce death after ED discharge.

\section{Strengths and limitations}

This exploratory study adds a unique Canadian perspective to existing data. Without controls, this study is hypothesisgenerating only; it does not provide a predictive tool for clinical use. The study requirement for all patient information to be accessible through our study sites' electronic medical records limited our population to those re-presenting to our facilities. It is unknown whether patients sought care at other hospitals after discharge. We did not have access to coroner, EMS, or other hospitals' data; obtaining this information would optimize future study data. We selected a consecutive cohort, which risked bias. We chose a consecutive sampling as one way to mitigate selection bias when random sampling was not feasible. The large proportion of excluded cases is another potential source of bias. Finally, knowing the outcomes of each case when reviewing them for potential medical error could lead to skewed interpretation of the care provided, which we mitigated through standardized reviewer training.

\section{Conclusion}

Though the frequency of related and unanticipated deaths and those due to medical error within 7 days of ED discharge was low, clinicians should carefully consider the highlighted common patient, provider, and system themes to facilitate safe discharge from the ED. The data from this exploratory study highlight opportunities to potentially enhance safe discharge from the ED and potentially decrease rates of medical error surrounding ED discharge.

Supplementary Information The online version contains supplementary material available at https://doi.org/10.1007/s43678-021-00190-z.

Acknowledgements Muhammad Mukarram, Soo-Min Kim, and John MacIsaac.

Author contributions RH, VT LAC conceived and designed the study. $\mathrm{RH}$ undertook data abstraction, and managed the data. KYL collected data; VT provided statistical advice on the study design and analysis. $\mathrm{KS}$ and AW were the 2nd and 3rd data abstracters and reviewers as well as providing advice on study conception and design. $\mathrm{RH}$ drafted the manuscript, and all authors contributed substantially to its revision. RH takes responsibility for the paper as a whole.

Funding None.

\section{Declarations}

Conflict of Interest The authors does not have any conflict of interest.

\section{References}

1. Brennan TA, Leape LL, Laird NM, Hebert L, Lacalio AR, Lawthers AG, Newhouse JP, Weiler PC, Hiatt HH. Incidence of adverse events and negligence in hospitalized patients: results of the Harvard Medical Practice Study. N Engl J Med. 1991;324(4):370-6.

2. Sklar DP, Crandall CS, Loellger E, Edmunds K, Paul I, Helltzer DL. Unanticipated death after discharge home from the emergency department. Ann Emerg Med. 2007;49:6.

3. Kohn LT, Corrigan JM, Donaldson MS, eds. To err is human: building a safer health System. US Institute of Medicine, Committee on Quality of Health Care in America. Washington, DC: National Academies Press; 2000.

4. Obermeyer Z, Cohn B, Wilson M, Jena AB, Cutler DM. Early death after discharge from emergency departments: analysis of national US insurance claims data. BMJ. 2017;356:j239.

5. Kobewka DM, Walraven CV, Turnbull J, Worthington J, Calder L, Forster A. Quality gaps identified through mortality review. BMJ Qual Saf. 2016;26(2):141-9.

6. Calder LA, Pozgay A, Riff S, Rothwell D, Youngson E, Mojaverian N, Cwinn AA, Forster A. Adverse events in patients with return emergency department visits. BMJ Qual Saf. 2014. https:// doi.org/10.1136/bmjqs-2014-003194.

7. Calder LA, Forster A, Nelson M, Leclair J, Perry J, Vaillancourt C, Hebert G, Cwinn AA, Wells G, Stiell I. Adverse events among patients registered in high-acuity areas of the emergency department: a prospective cohort study. Can J Emerg Med. 2010;12(5):421-30.

8. Forster AJ, Rose NGW, van Walraven C, Stiell I. Adverse events following an emergency department visit. Qual Saf Health Care. 2007;16:17-22. https://doi.org/10.1136/qshc.2005.017384.

9. Calder L, Pozgay A, Riff S, Rothwell D, Youngson E, Mojaverian $\mathrm{N}$, Cwinn A, Forster A. Adverse events in patients with return emergency department visits. BMJ Qual Saf. 2015;24:142-8. https://doi.org/10.1136/bmjqs-2014-003194.

10. Calder LA, Perry J, Yan JW, De Gorter R, Sivilotti MLA, Eagles D, Myslik F, Borgundvaag B, Émond M, McRae AD, Taljaard M, Thiruganasambandamoorthy V, Cheng W, Forster AJ, Stiell IG. Adverse events among emergency department patients with cardiovascular conditions: a multicenter study. Ann Emerg Med. 2021. https://doi.org/10.1016/j.annemergmed.2020.12.012. 